\title{
Pharmacokinetic Study of Ethambutol and Amikacin in Rat Lung Tissue Detected by UPLC-MS Method
}

\author{
Lin Yin ${ }^{1 \#, ~ H u i c h u n ~ S h i ~}{ }^{1 \#}$, Mengting Chen ${ }^{1,2}$, Jianglei Yu${ }^{1,2}$, Ping Jiao ${ }^{2}$ and Lijun Zhang*1 \\ ${ }^{1}$ Shanghai Public Health Clinical Center, Fudan University, China \\ ${ }^{2}$ School of Chemistry and Chemical Engineering, Hubei Polytechnic University, China \\ ${ }^{\#}$ These authors equally contributed to this study
}

*Corresponding author: Lijun Zhang, Shanghai Public Health Clinical Center, Fudan University, China

\section{ARTICLE INFO}

Received: 幽 February 05, 2021

Published: 慧 February 18, 2021

Citation: Lin Yin, Huichun Shi, Mengting Chen, Jianglei Yu, Ping Jiao, Lijun Zhang. Pharmacokinetic Study of Ethambutol and Amikacin in Rat Lung Tissue Detected by UPLC-MS Method. Biomed J Sci \& Tech Res 34(1)-2021. BJSTR. MS.ID.005489.

Abbreviations: TB: Tuberculosis; EMB: Ethambutol; AMK: Amikacin; TCA: Trichloroacetic Acid; MDR : MultidrugResistant;XDR: Extensively Drug-Resistant; TDM: Therapeutic Drug Monitoring; INH: Isoniazid; FQ: Fluoroquinolone; CAP: Capreomycin, KAN: Kanamycin; CLA: Clofazimine, MOX: Moxifloxacin; LFX: Levofloxacin; LZD: Linezolid; USP: United States Pharmacopeia; QC: Quality Control

\section{ABSTRACT}

Lower drug concentrations at tuberculosis (TB) infection sites may result in drug resistance. Understanding the tissue penetration of anti-TB drugs will offer new clues for optimizing drug dose. In this work, we performed pharmacokinetic study of ethambutol (EMB) and amikacin (AMK) in rat lung. Herein, a total of 160 rats were randomized to 16 time points, including before dosing ( $0 \mathrm{~h})$, and after dosing $0.25,0.33,0.5,0.67,1.0,1.5$, $2.0,2.5,3.0,4.0,8.0,9.0,12.0,16.0$ and $24.0 \mathrm{~h}$. The drug doses were $90 \mathrm{mg} / \mathrm{kg}$ intragastric administration for EMB, and $0.20 \mathrm{mg} / \mathrm{kg}$ intramuscular injection for AMK. The lung homogenate was precipitated with $15 \%$ trichloroacetic acid (TCA), diluted with $20 \%$ acetonitrile with $0.1 \%$ formic acid and $2 \%$ heptafluorobutyric acid. The compounds were detected by UPLC-MS/MS. The linear range detected by UPLC-MS/MS was from 10 to $5000 \mathrm{ng} / \mathrm{mL}\left(\mathrm{r}^{2} \geq 0.99\right)$ for both drugs. The maximum tissue concentrations $\left(\mathrm{C}_{\max }\right)$ were 39890 and $13855 \mathrm{ng} / \mathrm{mL}$ at $2.25 \mathrm{~h}$ for EMB and $0.40 \mathrm{~h}$ for AMK, respectively. The terminal elimination half-life $\left(\mathrm{t} 1 / \mathrm{2}_{\mathrm{z}}\right)$ was approximately of $3.43 \mathrm{~h}$ and $14.56 \mathrm{~h}$, respectively. Their estimated tissue penetration ratios were $107 \%$ for EMB and $0.1 \%$ for AMK. In conclusion, in this work, a simple UPLC-MS method was developed to perform PK study of EMB and AMK in rat model. Although it is animal PK study, our work might provide a reference for the lung lesion concentration in TB patients. It is necessary to pay attention to AMK usage in severe pulmonary tuberculosis due to its low penetration.

Keywords: Pharmacokinetics; UPLC-MS/MS; Tuberculosis; Lung; EMB; AMK

\section{Introduction}

Despite previous successes in management of tuberculosis (TB), the global emergence of multidrug-resistant TB (MDRTB) and extensively drug-resistant (XDR)-TB has become highly problematic and has led to high mortality [1]. Poor outcome may be due to poor treatment adherence, lack of drugs and lower drug exposure, especially at the site of disease [2-6]. Therapeutic drug monitoring (TDM) of TB drugs has been used to optimize clinical treatment by measuring systemic drug levels in blood/plasma as a guide for individual dose adjustments [2,7-9]. In MDR and XDRTB treatment, first-line drugs such as EMB and isoniazid (INH) and second-line drugs are usually combined [10]. These second line drugs include several fluoroquinolone (FQ) compounds as well as the injectable drugs AMK, capreomycin (CAP), and kanamycin (KAN)
[11]. According to previous reports, the concentration of some drugs in plasma is lower than the recommend ranges [8,11], and much lower in disease tissues including lung. Recently, researchers have tested drug concentrations in lung tissue [12,13], and lesion sites [13], as well as the dialysate [12-14] in the pulmonary cavity, to understand the drug penetration of lung tissue. It was found that clofazimine (CLA), moxifloxacin (MOX) and levofloxacin (LFX) has higher tissue penetration, RIF, PZA and linezolid (LZD) with median, and INH and KAN lower $[12,13]$. However, so far, the knowledge of the penetration of AMK and EMB in lung tissues was very limited. In this work, we developed an UPLC-MS/MS method to quantify AMK and EMB concentration in lung tissues, and carried out pharmacokinetic study in rat model. 


\section{Materials and Methods}

\section{Chemicals and Reagents}

EMB was purchased from United States Pharmacopeia (USP) with purity of 100\%, EMB-d4 (the internal standard (IS) of EMB) from Toronto Research Chemicals with purify of $98 \%$ in chemical, 99.3\% in isotopic and $97.49 \%$ in d4 component. AMK was from China Institute for the Control of Pharmaceutical and Biological Products with purity of $\geq 74.91 \%$, Apramycin sulfate (APM; the IS of AMK) from Dr. Ehrenstorfer, with the purity of $89.6 \%$. HPLC grade methanol and acetonitrile were brought from Merck (Merck, Darmstadt, Germany). Ultra-pure water was made using the Milli-Q system (Millipore, Bedford, MA, USA). Other regents and solvents were chromatographically pure and from Guoyao Company.

\section{UPLC-MS/MS Conditions}

The UPLC-MS/MS system consisted of a Waters Acquity UPLC (Waters Corporation, Milford, USA) and an AB Sciex Triple Quad 5500 (AB SCIEX company, Boston, USA). The chromatographic separation of EMB and AMK, and their ISs were conducted on an ACQUITY UPLC HSS T3 column $(2.1 \mathrm{~mm} \times 100 \mathrm{~mm}, 1.8 \mu \mathrm{m})$. A $5-\mu \mathrm{L}$ sample was loaded and eluted with a gradient of water containing $0.1 \%$ FA (A) and ACN containing $0.1 \%$ FA (B), at $0.35 \mathrm{~mL} / \mathrm{min}$ flow rate with the flowing program: $0-1.5 \mathrm{~min}, 2-80 \% \mathrm{~B} ; 1.5-2.0 \mathrm{~min}$, $80 \% ; 2.0-2.01 \mathrm{~min}, 80-2 \% ; 2.01-3.0 \mathrm{~min}, 2 \%$. The analytes were detected by multiple reaction monitoring (MRM) mode.

Preparation of Standard Curve and Quality Control

\section{Solution}

The stock solutions of EMB and AMK, at a concentration of $1.0 \mathrm{mg} / \mathrm{mL}$, were prepared using $10 \%$ methanol, and stored at -80 ${ }^{\circ} \mathrm{C}$. The working solutions containing EMB and AMK were prepared by diluting the mixed stock solution with $20 \%$ methanol to obtain different concentrations $(25,000,22,500,5000,1000,500,100$, $50 \mathrm{ng} / \mathrm{mL}$ ). The IS working solutions were prepared with $20 \%$ methanol to obtain the concentration of $0.25 \mu \mathrm{g} / \mathrm{mL}$ for EMB-d4, and $5 \mu \mathrm{g} / \mathrm{mL}$ for APM. All working solutions were stored at $4{ }^{\circ} \mathrm{C}$. The standard curves and the quality control (QC) samples containing EMB and AMK, were obtained by mixing the corresponding working solutions ( $40 \mu \mathrm{L})$, IS $(40 \mu \mathrm{L})$ with $200 \mu \mathrm{L}$ of blank tissue homogenate. The final concentrations were 5000,4500, 1000, 200, 100, 20, $10 \mathrm{ng} / \mathrm{mL}$ for the standard curve, and 10, 40, 400, and 4000ng/mL for LLOQ LQC, MQC and HQC.

\section{Sample Preparation}

Tissue homogenate $(200 \mu \mathrm{L}), 40 \mu \mathrm{L}$ IS and $40 \mu \mathrm{L} 20 \%$ methanol were mixed, and protein precipitated by $480 \mu \mathrm{L}$ trichloroacetic acid (TCA) at the concentration of $15 \%$. The mixture was vortexed for $3 \mathrm{~min}$ and centrifuged at $12,000 \mathrm{rpm}$ at $4{ }^{\circ} \mathrm{C}$ for $10 \mathrm{~min}$. Then the supernatant $(100 \mu \mathrm{L})$ was diluted with $100 \mu \mathrm{L}$ solution $(20 \%$ ACN, $0.1 \% \mathrm{FA}$ and $2 \% \mathrm{HFBA}$, and transferred to an auto-sampler for analysis by UHPLC-MS/MS. The injected volume was $5 \mu \mathrm{L}$.

\section{Method Validation}

Method validation was performed according to Chinese pharmacopoeia 2015, and FDA guidelines [15]. The method was validated for selectivity, carryover, linearity, accuracy, precision, matrix effect, recovery, and stability. The details were shown in the supplement materials.

\section{Pharmacokinetic study in Rat}

All animal experiments were performed in accordance with the Animal Care and Use Guideline, and authorized by the Animal Care and Use of Committee of Shanghai Public Health Clinical Center (2017-S017-02). Sprague-Dawley rats $(n=160$, equal mix of male and female, weight $180 \pm 20 \mathrm{~g}$ ) were obtained from Shanghai Public Health Clinical Center (Shanghai, China). The animals were housed in an air-conditioned room with temperature of $23-26{ }^{\circ} \mathrm{C}$, relative humidity of $40 \%-60 \%$, and light of $12 \mathrm{~h}$ on and $12 \mathrm{~h}$ off. Food and water were freely available. Rats were randomly assigned to 16 time points, including before dosing $(0 \mathrm{~h})$, and after dosing 0.25 , $0.33,0.5,0.67,1.0,1.5,2.0,2.5,3.0,4.0,8.0,9.0,12.0,16.0$ and $24.0 \mathrm{~h}$. After a 7-day adaption, all animals were fasted overnight, and used for experiments. EMB was administered at $90 \mathrm{mg} / \mathrm{kg}$ [intragastric administration (i.g.)] and AMK at $20 \mathrm{mg} / \mathrm{kg}$ [intramuscular injection (i.m.)]. The rats were euthanized at different time points. The lung tissues were collected, homogenized in PBS (weight to volume of $1: 5, \mathrm{w}: \mathrm{v}$ ), and centrifuged at $12,000 \mathrm{rpm}$ for $10 \mathrm{~min}$. The supernatants were collected and stored at $-80{ }^{\circ} \mathrm{C}$ until further analysis.

\section{Data Analysis}

All data were expressed as mean \pm standard deviation (SD). The PK analysis was performed in DAS 2.0 software, and PK parameters from non-compartment model were collected, including Cmax (the maximal drug plasma concentration); $\mathrm{T}_{\max }$ (the time to reach $\mathrm{C}_{\max }$ ); $\mathrm{AUC}_{0-\mathrm{t}}$ (the area under the plasma concentration-time curve from 0 to the time $\mathrm{t}$ ); $\mathrm{AUC}_{0-\infty}$ (the area under the plasma concentrationtime curve from 0 to infinity); $t_{1 / 2}$ (the elimination half-life); $C L$ (clearance), and Vd (apparent volume of distribution).

\section{Incurred Sample Reanalysis}

An incurred sample reanalysis (ISR) was carried out to evaluate the reproducibility of the analytical method. Two samples from each time point were randomly selected, except that before dosing, after dosing at 4.0,12.0, and 24.0h. Not enough volume was left for the samples at 4.0 and $12.0 \mathrm{~h}$ time points. The receipt standard for ISR was a percentage change less than $20 \%$ in $67 \%$ samples.

\section{Supplement Methods}

Selectivity and Carryover: To investigate the selectivity of the method, six different sources of blank rat lung tissue homogenate were used to make blank, blank spiked with EMB (IS, EMB-d4) and AMK (IS, APM) at the concentration of LLOQ. In addition, lung tissues from a rat after an administration of EMB and AMK for $3 \mathrm{~h}$ 
were prepared. The presence of interfering peaks in the retention times of the analytes and their ISs was evaluated. Carryover was checked by analyzing a blank matrix sample following HQC.

Linearity: Seven standard curve samples with a series of concentrations ranging from $10-5000 \mathrm{ng} / \mathrm{mL}$ were prepared as described in "Preparation of standard curve and quality control solution" The analyte-to-IS peak ratios were plotted against the corresponding EMA or AMK concentrations.

Intraday and Interday Precision and Accuracy: Six replicates of LLOQ, LQC, MQC and HQC samples were prepared and analyzed on the same batch and on different batches to determine the intraday and interday precisions and accuracy.

Recovery and Matrix Effect: Extraction recovery was determined by comparing the peak areas of the analyte and IS obtained from the QC samples with those from post-extraction spiked samples $(n=6)$. The matrix effect was calculated by comparing the mean peak areas of QC standards added into postextracted blank matrix samples with that of pure standard solution at the same concentration.

Stability: Two kinds of QC samples (HQC and LQC; $n=6$ ) were used to evaluate the stability of EMB and AMK in rat lung homogenate under different storage conditions including:

1) Storage at room temperature, or $4^{\circ} \mathrm{C}$ for $24 \mathrm{~h}$ before extraction,
2) Storage at room temperature or $4{ }^{\circ} \mathrm{C}$ for $24 \mathrm{~h}$ after extraction,

3) The stability of freeze-thaw performed by storing at -80 ${ }^{\circ} \mathrm{C}$ and thawing at room temperature every $24 \mathrm{~h}$ for three cycles,

4) Storage at $-80^{\circ} \mathrm{C}$ for 30 days.

\section{Results}

\section{UPLC-MS Method}

Method Development: After optimizing the mass spectrometry parameters, EMB, EMB-d4, AMK, and APM were detected to have suitable MRM ion pairs of $\mathrm{m} / \mathrm{z}$ 205.1/116.1 for EMB, 209.1/120.2 for EMB-d4, 586.3/425.3 for AMK, and 540.1/217.1 for APM. For chromatograph condition, since EMB and AMK have strong hydrophilicity, we investigated different protein precipitation methods, and dilution solutions at the last step for sample treatment. Our results showed that 15\% TCA gave good extraction recovery, and $20 \%$ ACN with $0.1 \%$ FA and 2\% HFBA improved the chromatographic retention capacity of AMK. Representative chromatograms were shown in (Figure 1). Our results showed that there was no significant interference observed from rat lung homogenate at the retention time of EMB, AMK, and their ISs (EMB-d4 and APM). Furthermore, no carryover from residues on the column was observed from the blank lung homogenate after an HQC injection.
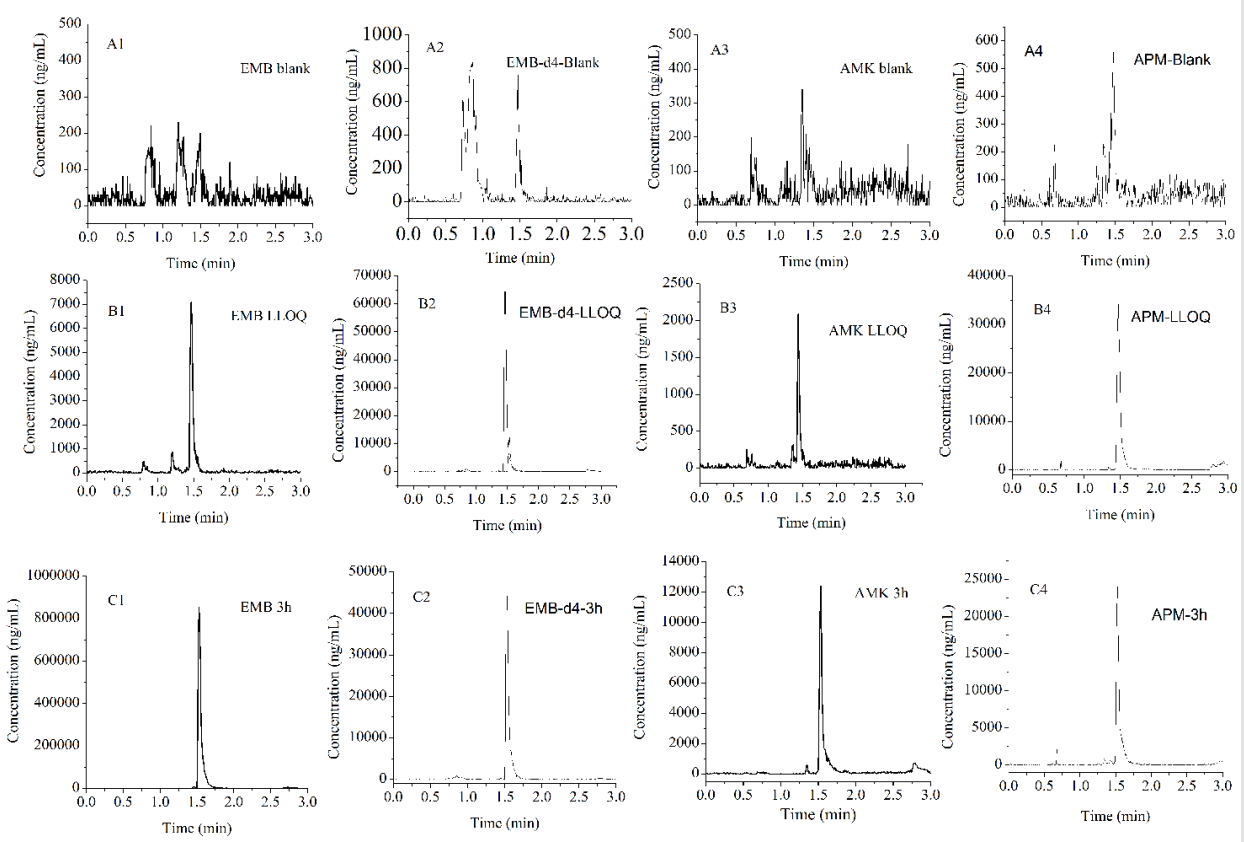

Figure 1: The representative MRM chromatograms of EMB, AMK, and their ISs.

A. $\quad \mathrm{EMB}(\mathrm{A} 1), \mathrm{EMB}-\mathrm{d} 4$ (A2), AMK (A3) and APM (A4) in blank rat lung homogenate loaded after HQC;

B. Blank rat lung homogenate spiked with EMB (B1), and AMK (B3) at LLOQ, and their ISs (EMB-d4 (B2)and APM (B4) );

C. Rat lung homogenate of EMB (C1), and AMK (C3) at $3 \mathrm{~h}$ after i.g. EMB and i.m. AMK, and spiked with EMB-d4 (C2) and $\mathrm{APM}(\mathrm{C} 4)$. 
Method Validation: The approach provided good linearity in the range of $10-5000 \mathrm{ng} / \mathrm{mL}$ for both EMB and AMK in rat lung homogenate. The lower limit of quantification (LLOQ) was both $10 \mathrm{ng} / \mathrm{mL}$. The intraday accuracy ranged from $-5.52 \%$ to $1.8 \%$ for $\mathrm{EMB}$ and $-6.6 \%$ to $7.08 \%$ for AMK, respectively. The interday accuracy ranged from $0.43 \%$ to $3.36 \%$ for EMB and $-2.57 \%$ to $5 \%$ for AMK, respectively. The intraday and interday precision of EMB and AMK were all less than $11.14 \%$. These data indicated that the method had good precision and accuracy (Table 1). The mean recovery rate of IS normalized EMB and AMK ranged from $98.62 \%$ to $106.12 \%$ and $97.01 \%-104.22 \%$, respectively. The matrix effects were from $96.33 \%-104.14 \%$ for EMB, and $94.23 \%-104.38 \%$ for AMK (Table 2). The pre- and post-preparative, freeze-thaw, and long-term stability were measured by comparing six replicates of two QC samples (low and high levels) of EMB and AMK. As shown in (Table 3), the stability results (RSD\% and RE\%) were all less than $15 \%$ in rat lung homogenate under six storage conditions: room temperature or $4^{\circ} \mathrm{C}$ for $24 \mathrm{~h}$ pre- or post- preparation, freeze-thaw, and $-80^{\circ} \mathrm{C}$ for 30 days.

Table 1: Intraday and interday precision, the accuracy of EMB and AMK in rat lung $(n=6)$.

\begin{tabular}{|c|c|c|c|c|c|c|c|}
\hline \multirow[b]{2}{*}{ Drug Name } & \multirow{2}{*}{$\begin{array}{c}\text { Spiked } \\
\text { Concentration } \\
(\mathrm{ng} / \mathrm{mL})\end{array}$} & \multicolumn{3}{|c|}{ Intraday } & \multicolumn{3}{|c|}{ Interday } \\
\hline & & $\begin{array}{c}\text { Measured (ng/ } \\
\text { mL) }\end{array}$ & Precision(\%) & Accuracy $(\%)$ & Measured (ng/mL) & Precision(\%) & Accuracy $(\%)$ \\
\hline \multirow{4}{*}{ EMB } & 10 & $9.45 \pm 0.63$ & 6.71 & -5.52 & $10.34 \pm 1.14$ & 11.06 & 3.36 \\
\hline & 40 & $40.35 \pm 1.47$ & 3.65 & 0.90 & $40.92 \pm 2.80$ & 6.84 & 2.30 \\
\hline & 400 & $396.4 \pm 4.77$ & 1.20 & -0.90 & $401.73 \pm 29.09$ & 7.24 & 0.43 \\
\hline & 4000 & $4072 \pm 85.56$ & 2.10 & 1.80 & $4090.67 \pm 204.78$ & 5.01 & 2.27 \\
\hline \multirow{4}{*}{ AMK } & 10 & $10.71 \pm 0.88$ & 8.18 & 7.08 & $10.35 \pm 1.05$ & 10.10 & 3.49 \\
\hline & 40 & $37.36 \pm 4.07$ & 10.89 & -6.60 & $38.97 \pm 4.34$ & 11.14 & -2.57 \\
\hline & 400 & $391.6 \pm 22.51$ & 5.75 & -2.10 & $406.8 \pm 25.75$ & 6.33 & 1.70 \\
\hline & 4000 & $4064 \pm 259.77$ & 6.39 & 1.60 & $4200 \pm 188.53$ & 4.49 & 5.00 \\
\hline
\end{tabular}

Table 2: Extraction recoveries and matrix effects of EMB and AMK after IS normalized $(n=6)$.

\begin{tabular}{|c|c|c|c|c|}
\hline \multirow{2}{*}{$\begin{array}{c}\text { Spiked Concentration } \\
\text { (ng/mL) }\end{array}$} & EMB & AMK & EMB & Extraction Recovery (\%) \\
\cline { 2 - 5 } & 104.14 & 96.85 & 98.62 & 97.01 \\
\hline 40 & 103.78 & 104.38 & 100.34 & 102.01 \\
\hline 400 & 96.33 & 94.23 & 106.12 & 104.22 \\
\hline
\end{tabular}

Table 3: Stability of EMB and AMK in rat lung homogenate under different storage conditions (n=6).

\begin{tabular}{|c|c|c|c|c|c|}
\hline \multirow{2}{*}{ Compounds } & \multirow{2}{*}{ Storage conditions } & \multicolumn{2}{|c|}{ Concentration(ng/mL) } & \multirow{2}{*}{ RSD (\%) } & \multirow{2}{*}{ RE (\%) } \\
\hline & & Spiked & Measured & & \\
\hline \multirow{12}{*}{ EMB } & \multirow{2}{*}{ Room temperature for $24 \mathrm{~h}$ pre-preparation } & 40 & 44.47 & 2.5 & 11.18 \\
\hline & & 4000 & 4195.67 & 2.33 & 4.89 \\
\hline & \multirow{2}{*}{$4{ }^{\circ} \mathrm{C}$ for $24 \mathrm{~h}$ pre-preparation } & 40 & 45.51 & 6.81 & 13.78 \\
\hline & & 4000 & 3999.17 & 11.15 & -0.02 \\
\hline & \multirow{2}{*}{ Room temperature for $24 \mathrm{~h}$ post-preparation } & 40 & 45.04 & 4.72 & 12.60 \\
\hline & & 4000 & 4115.97 & 5.52 & 2.90 \\
\hline & \multirow{2}{*}{ Autosampler $\left(4^{\circ} \mathrm{C}\right)$ for $24 \mathrm{~h}$} & 40 & 44.38 & 4.37 & 10.94 \\
\hline & & 4000 & 4131.67 & 2.5 & 3.29 \\
\hline & \multirow{2}{*}{ Three-freeze-thaw cycles } & 40 & 42.08 & 1.71 & 5.21 \\
\hline & & 4000 & 4038.89 & 3.91 & 0.97 \\
\hline & \multirow{2}{*}{ Long term $\left(-80^{\circ} \mathrm{C}\right)$ for 30 days } & 40 & 43.25 & 8.78 & 8.12 \\
\hline & & 4000 & 4080.4 & 3.45 & 2.01 \\
\hline
\end{tabular}




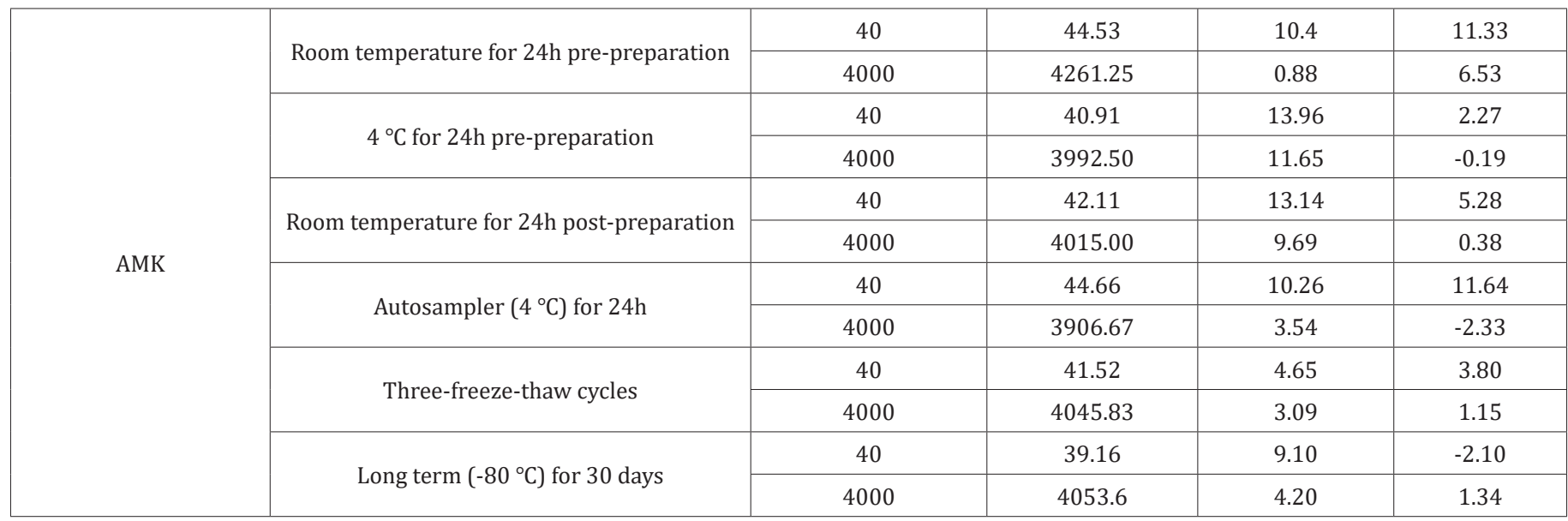

\section{Pharmacokinetic Results}

The concentration of EMB (i.g.) and AMK (i.m.) in lung homogenate from 16 time points $(\mathrm{n}=10)$ was determined using the newly developed UPLC-MS/MS approach. Statistical analysis of PK was performed by DAS 2.0 software (Tables S1 \& S2). The pharmacokinetic parameters of EMB and AMK using the noncompartmental model were listed in (Table 4). Mean concentrationtime curves of EMB and AMK in lung tissue were shown in (Figure 2). EMB and AMK reached a Cmax of 39890 and $13855 \mathrm{ng} / \mathrm{mL}$ at
2.25 an $0.40 \mathrm{~h}$, with $\mathrm{t} 1 / 2_{\mathrm{z}}$ of 3.43 and $14.56 \mathrm{~h}, \mathrm{~V}_{\mathrm{z}} / \mathrm{F}$ of 3.07 and $0.014 \mathrm{~L} / \mathrm{kg}$, respectively. Their estimated doses (using AUC* $\mathrm{V}^{*} \mathrm{k}$ ) in lung tissue are $97.6 \mathrm{mg} / \mathrm{kg}$ (about $107 \%$ of i.g. dose $(90 \mathrm{mg} / \mathrm{kg}$ )) and $0.20 \mathrm{mg} / \mathrm{kg}$ (only about $0.1 \%$ of i.m. dose $(20 \mathrm{mg} / \mathrm{kg}$ )) for EMB and AMK, respectively. In order to detect the accuracy of analysis results, we performed ISR of 24 samples. As shown in (Table 5), the differences between ISR and initial concentration were less than $20 \%$ of their mean value except 2 samples including one $30 \mathrm{~min}$ time sample with $30.3 \%$ for EMB, and one 20 min time sample with $-21.7 \%$ for AMK.

Table S1: The detected concentration of EMB in the lung homogenate of pharmacokinetic rat model.

\begin{tabular}{|c|c|c|c|c|c|c|c|c|c|c|c|c|c|}
\hline $\mathbf{t}$ & No1 & No2 & No3 & No4 & No5 & No6 & No7 & No8 & No9 & No10 & Mean & SD & RSD/\% \\
\hline 0 & 0 & 0 & 0 & 0 & 0 & 0 & 0 & 0 & 0 & 0 & 0 & & \\
\hline 0.25 & 153 & 353 & 746 & 166 & 75 & 127 & 526 & 501 & 969 & 555 & 417.1 & 296.045 & 70.977 \\
\hline 0.33 & 303 & 482 & 1030 & 264 & 237 & 560 & 600 & 100 & 1200 & 1300 & 607.6 & 425.926 & 70.1 \\
\hline 0.5 & 2410 & 4160 & 1670 & 960 & 1900 & 716 & 827 & 4260 & 1500 & 1800 & 2020.3 & 1267.204 & 62.724 \\
\hline 0.67 & 4050 & 5330 & 3380 & 3540 & 4410 & 1150 & 5000 & 10000 & 5000 & 10000 & 5186 & 2800.636 & 54.004 \\
\hline 1 & 19300 & 19300 & 14500 & 21200 & 19400 & 4700 & 6700 & 18600 & 9860 & 24800 & 15836 & 6653.659 & 42.016 \\
\hline 1.5 & 17900 & 20900 & 38100 & 34400 & 27700 & 5860 & 17600 & 21800 & 23400 & 14900 & 22256 & 9399.138 & 42.232 \\
\hline 2 & 16700 & 22500 & 29300 & 26900 & 28600 & 12900 & 18100 & 15300 & 10800 & 16000 & 19710 & 6675.902 & 33.871 \\
\hline 2.5 & 16500 & 23500 & 25700 & 20200 & 26500 & 23000 & 22300 & 12500 & 9580 & 14200 & 19398 & 5853.891 & 30.178 \\
\hline 3 & 13300 & 30900 & 18900 & 17900 & 17300 & 8900 & 17300 & 15300 & 8900 & 21700 & 17040 & 6391.696 & 37.51 \\
\hline 4 & 8700 & 12300 & 15800 & 15100 & 19700 & 8170 & 15100 & 15000 & 4470 & 13600 & 12794 & 4479.031 & 35.009 \\
\hline 8 & 5250 & 8730 & 6090 & 11600 & 5780 & 3390 & 8600 & 12500 & 3350 & 2900 & 6819 & 3418.559 & 50.133 \\
\hline 9 & 4200 & 8540 & 6320 & 11600 & 4500 & 5420 & 6100 & 10300 & 300 & 1450 & 5873 & 3578.821 & 60.937 \\
\hline 12 & 2790 & 3830 & 1870 & 4050 & 2550 & 971 & 702 & 844 & 779 & 614 & 1900 & 1328.605 & 69.927 \\
\hline 16 & 788 & 1280 & 999 & 1620 & 188 & 466 & 365 & 2010 & 230 & 386 & 833.2 & 629.572 & 75.561 \\
\hline 24 & 467 & 478 & 438 & 351 & 350 & 674 & 372 & 188 & 436 & 371 & 412.5 & 123.961 & 30.051 \\
\hline
\end{tabular}

Table S2: The detected concentration of AMK in the lung homogenate of pharmacokinetic rat model.

\begin{tabular}{|c|c|c|c|c|c|c|c|c|c|c|c|c|c|}
\hline t & No1 & No2 & No3 & No4 & No5 & No6 & No7 & No8 & No9 & No10 & Mean & SD & RSD/\% \\
\hline 0 & 0 & 0 & 0 & 0 & 0 & 0 & 0 & 0 & 0 & 0 & & & \\
\hline 0.25 & 8550 & 11900 & 8750 & 8630 & 8560 & 6480 & 7950 & 5200 & 7220 & 5130 & 7837 & 1986.566 & 25.349 \\
\hline 0.33 & 8520 & 9950 & 11200 & 10400 & 7120 & 8480 & 9950 & 11200 & 10400 & 7120 & 9434 & 1530.833 & 16.227 \\
\hline 0.5 & 10300 & 11800 & 8120 & 19500 & 8740 & 7850 & 6320 & 10600 & 13200 & 10200 & 10663 & 3698.516 & 34.686 \\
\hline 0.67 & 5870 & 8830 & 8680 & 6840 & 8080 & 6360 & 5000 & 8000 & 9000 & 8800 & 7546 & 1426.287 & 18.901 \\
\hline
\end{tabular}




\begin{tabular}{|c|c|c|c|c|c|c|c|c|c|c|c|c|c|}
\hline 1 & 6660 & 4560 & 4860 & 6360 & 7200 & 4220 & 4970 & 4660 & 3880 & 5920 & 5329 & 1125.546 & 21.121 \\
\hline 1.5 & 2180 & 3070 & 3160 & 3780 & 3330 & 1560 & 1950 & 2110 & 2890 & 2650 & 2668 & 700.853 & 26.269 \\
\hline 2 & 1360 & 2250 & 2500 & 1730 & 1990 & 1580 & 1550 & 1090 & 1070 & 1710 & 1683 & 465.022 & 27.631 \\
\hline 2.5 & 1230 & 2060 & 1940 & 1790 & 3090 & 1170 & 1340 & 1760 & 1710 & 957 & 1704.7 & 606.843 & 35.598 \\
\hline 3 & 2040 & 2580 & 2400 & 1670 & 1250 & 1050 & 1100 & 986 & 1170 & 1020 & 1526.6 & 607.209 & 39.775 \\
\hline 4 & 643 & 537 & 639 & 449 & 609 & 904 & 544 & 591 & 590 & 660 & 616.6 & 118.696 & 19.25 \\
\hline 8 & 451 & 629 & 512 & 695 & 579 & 431 & 135 & 864 & 462 & 505 & 526.3 & 191.046 & 36.3 \\
\hline 9 & 651 & 499 & 425 & 555 & 2210 & 424 & 868 & 613 & 543 & 417 & 720.5 & 540.787 & 75.057 \\
\hline 12 & 442 & 370 & 295 & 384 & 322 & 324 & 345 & 337 & 492 & 397 & 370.8 & 60.319 & 16.267 \\
\hline 16 & 300 & 372 & 349 & 393 & 309 & 322 & 132 & 133 & 133 & 134 & 257.7 & 110.787 & 42.991 \\
\hline 24 & 436 & 394 & 372 & 267 & 382 & 715 & 395 & 329 & 564 & 418 & 427.2 & 126.597 & 29.634 \\
\hline
\end{tabular}

Table 4: Main pharmacokinetic parameters of EMB and AMK in rat lung after i.g. and i.m. administration.

\begin{tabular}{|c|c|c|c|}
\hline Parameters & Unit & i.g. EMB & i.m. AMK \\
\hline Dose & $\mathrm{mg} / \mathrm{kg}$ & 90 & 20 \\
\hline $\mathrm{AUC}_{(0-\mathrm{t})}$ & $\mu \mathrm{g} / \mathrm{L} \cdot \mathrm{h}$ & $155,715.03$ & $23,011.06$ \\
\hline $\mathrm{AUC}_{(0-\infty)}$ & $\mu \mathrm{g} / \mathrm{L} \cdot \mathrm{h}$ & $157,280.69$ & $29,252.39$ \\
\hline $\mathrm{CL}_{\mathrm{z} / \mathrm{F}}$ & $\mathrm{L} / \mathrm{h} / \mathrm{kg}$ & 0.62 & 0.001 \\
\hline $\mathrm{V}_{\mathrm{z} / \mathrm{F}}$ & $\mathrm{L} / \mathrm{kg}$ & 3.07 & 0.014 \\
\hline $\mathrm{MRT}_{(0-\mathrm{t})}$ & $\mathrm{h}$ & 5.06 & 4.78 \\
\hline $\mathrm{MRT}_{(0-\infty)}$ & $\mathrm{h}$ & 5.32 & 14.47 \\
\hline $\mathrm{C}_{\max }$ & $\mu \mathrm{g} / \mathrm{L}$ & 39,890 & 13,855 \\
\hline $\mathrm{t}_{1 / 2}$ & $\mathrm{~h}$ & 3.43 & 14.56 \\
\hline $\mathrm{T}_{\max }$ & $\mathrm{h}$ & 2.25 & 0.40 \\
\hline
\end{tabular}

Table 5: Incurred sample reanalysis of EMB and AMK.

\begin{tabular}{|c|c|c|c|c|c|c|c|c|}
\hline \multirow{2}{*}{$\begin{array}{l}\text { Sampling } \\
\text { point }\end{array}$} & \multirow[b]{2}{*}{$\begin{array}{l}\text { Initial conc. } \\
\text { (ng/mL) }\end{array}$} & \multirow{2}{*}{$\begin{array}{c}\text { EMB } \\
\begin{array}{c}\text { Re-assay conc. } \\
(\mathrm{ng} / \mathrm{mL})\end{array}\end{array}$} & \multirow[b]{2}{*}{ Mean } & \multirow[b]{2}{*}{ Difference (\%) } & \multirow[b]{2}{*}{$\begin{array}{l}\text { Initial conc. } \\
\text { (ng/mL) }\end{array}$} & \multicolumn{2}{|l|}{ AMK } & \multirow[b]{2}{*}{ Difference (\%) } \\
\hline & & & & & & $\begin{array}{c}\text { Re-assay conc. (ng/ } \\
\text { mL) }\end{array}$ & Mean & \\
\hline $15 \mathrm{~min}-2$ & 80.4 & 70.5 & 75.5 & 13.1 & 3110 & 3160 & 3135 & -1.6 \\
\hline $15 \mathrm{~min}-3$ & 172 & 149 & 160.5 & 14.3 & 1930 & 2310 & 2120 & -17.9 \\
\hline $20 \min -1$ & 67.9 & 60.6 & 64.3 & 11.4 & 1810 & 2250 & 2030 & -21.7 \\
\hline $20 \min -3$ & 243 & 206 & 224.5 & 16.5 & 3400 & 2960 & 3180 & 13.8 \\
\hline $30 \min -1$ & 986 & 883 & 934.5 & 11.0 & 2250 & 2730 & 2490 & -19.3 \\
\hline $30 \mathrm{~min}-7$ & 224 & 165 & 194.5 & 30.3 & 1520 & 1660 & 1590 & -8.8 \\
\hline $40 \mathrm{~min}-4$ & 818 & 708 & 763 & 14.4 & 1520 & 1800 & 1660 & -16.9 \\
\hline $40 \min -6$ & 257 & 231 & 244 & 10.7 & 1530 & 1670 & 1600 & -8.8 \\
\hline $1 \mathrm{~h}-5$ & 4440 & 3880 & 4160 & 13.5 & 1810 & 1900 & 1855 & -4.9 \\
\hline $1 \mathrm{~h}-10$ & 6010 & 4960 & 5485 & 19.1 & 1550 & 1560 & 1555 & -0.6 \\
\hline $1.5 \mathrm{~h}-3$ & 9240 & 7620 & 8430 & 19.2 & 678 & 820 & 749 & -19.0 \\
\hline $1.5 \mathrm{~h}-8$ & 5080 & 4370 & 4725 & 15.0 & 536 & 541 & 538.5 & -0.9 \\
\hline $2 \mathrm{~h}-2$ & 5220 & 4500 & 4860 & 14.8 & 546 & 577 & 561.5 & -5.5 \\
\hline $2 \mathrm{~h}-5$ & 6620 & 5720 & 6170 & 14.6 & 453 & 508 & 480.5 & -11.4 \\
\hline $2.5 \mathrm{~h}-2$ & 5430 & 4700 & 5065 & 14.4 & 560 & 528 & 544 & 5.9 \\
\hline $2.5 \mathrm{~h}-10$ & 3210 & 2840 & 3025 & 12.2 & 196 & 233 & 214.5 & -17.2 \\
\hline $3 h-6$ & 5410 & 4600 & 5005 & 16.2 & 235 & 257 & 246 & -8.9 \\
\hline $3 h-9$ & 5310 & 4380 & 4845 & 19.2 & 306 & 291 & 298.5 & 5.0 \\
\hline $6 \mathrm{~h}-1$ & 2480 & 2240 & 2360 & 10.2 & 131 & 151 & 141 & -14.2 \\
\hline $6 h-8$ & 2330 & 2050 & 2190 & 12.8 & 164 & 141 & 152.5 & 15.1 \\
\hline
\end{tabular}




\begin{tabular}{|c|c|c|c|c|c|c|c|}
\hline $8 \mathrm{~h}-3$ & 1440 & 1220 & 1330 & 16.5 & 110 & 112 & -3.6 \\
\hline $8 \mathrm{~h}-5$ & 1390 & 1160 & 1275 & 18.0 & 139 & 14 & 132 \\
\hline $16 \mathrm{~h}-1$ & 190 & 158 & 174 & 18.4 & 59.2 & 57.7 & 58.45 \\
\hline $16 \mathrm{~h}-3$ & 226 & 200 & 213 & 12.2 & 60.7 & 70.8 \\
\hline
\end{tabular}
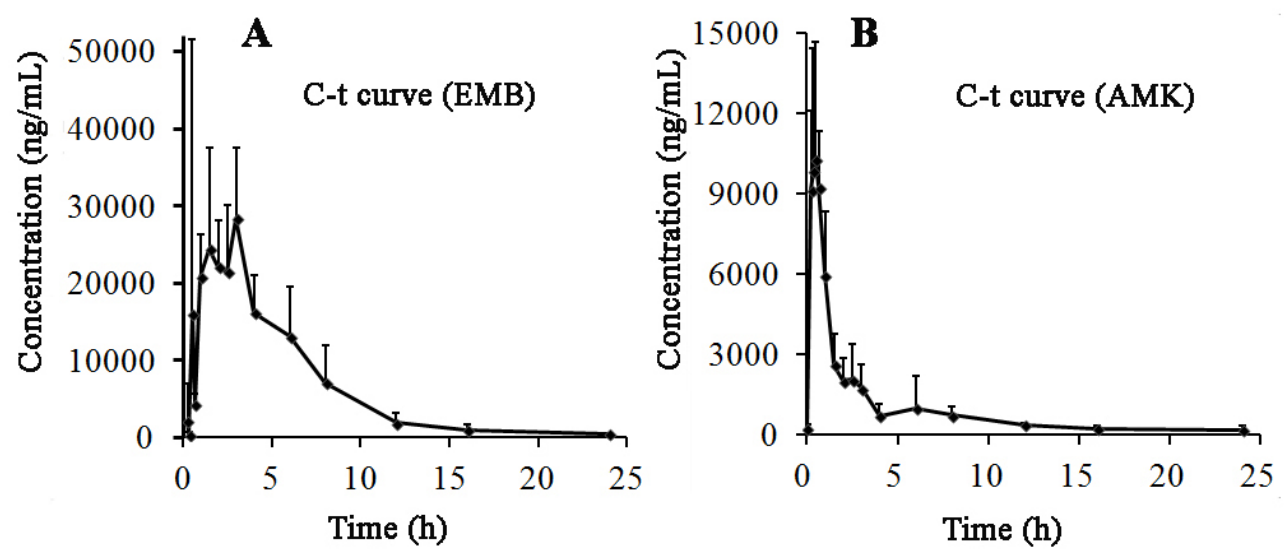

Figure 2: Mean plasma concentration-time curves of EMB (A) and AMK (B) after drug administration for 24h (n=10).

\section{Discussions}

Although there are methods reporting quantification of EMB [2,16-20] and AMK [17,21,22] in plasma [2,16-22], milk [21], muscle [21] and wastewater [23] singly, as well as simultaneously in plasma [24] and sputum [25] using LC-MS, no study has reported simultaneous quantification of EMB and AMK in lung tissues. In this work, we developed and validated a simple UPLC-MS/MS method, in which 15\% TCA was used for protein precipitation. TCA was chosen as it is dependent on the trichloro-group, and has higher extraction recovery for hydrophilic compounds (such as AMK) $[17,21,26]$. Furthermore, to improve the retention time of AMK (an aminoglycoside compound) in C18 column, an ion-pairing agent of HFBA was added. HFBA exhibited better retention of aminoglycosides on the analytical column and was also better at enhancing the electrospray process than other ion pair reagents $[27,28]$. The verified UPLC-MS/MS method was then used for quantitation in a PK study of EMB (i.p.) and AMK (i.m.). Our results showed that EMB had very strong lung penetration $(107 \%)$, however, AMK was very weak $(0.1 \%)$. The $C_{\text {max }}$ of AMK in lung detected in this work was similar to that previously reported $[29,30]$. Our results indicate that the developed method was available to detect the concentration of EMB and AMK in the lung tissues from MDR-TB patients.

\section{Conclusion}

In this work, a simple UPLC-MS method was developed to perform PK study of EMB and AMK in rat model. Although it is animal PK study, our work might provide a reference for the lung lesion concentration in TB patients. Our study showed that the lung penetration of AMK was very weak. It is necessary to pay attention to AMK usage in severe pulmonary tuberculosis due to its low penetration.

\section{Acknowledgment}

We would like to express our gratitude to the grant from National Science and Technology Program during the Thirteenth Fiveyear Plan Period, China (2017ZX09304027), Shanghai Municipal Commission of Health and Family planning (201640005), and the National Natural Science Funds, China (81271834). We would like to thank Editage (www.editage.com) for English language editing.

\section{Declarations}

Not applicable

\section{Conflicts of Interest/Competing Interests}

All authors declared no potential conflicts.

\section{Authors' Contributions}

a. Lijun Zhang: Conceptualization, Writing, Methodology, Formal analysis, Software, Investigation, Project administration, Funding acquisition.

b. Yin Lin: Resources, Investigation, Data Curation, Validation.

c. Huichun Shi: Writing, Investigation, Data Curation.

d. Chen Mengting: Data curation, Investigation, Methodology.

e. Yu Jianglei: Visualization, Investigation.

f. Ping Jiao: Data curation.

\section{References}

1. Dheda K, Gumbo T, Maartens G, Dooley KE, Mc Nerney R, et al. (2017) The epidemiology, pathogenesis, transmission, diagnosis, and management of multidrug-resistant, extensively drug-resistant, and incurable tuberculosis. Lancet Respir Med S2213-2600(17): 30079-30086. 
2. Davies Forsman L, Niward K, Hu Y, Zheng R, Zheng X, et al. (2018) Plasma concentrations of second-line antituberculosis drugs in relation to minimum inhibitory concentrations in multidrug-resistant tuberculosis patients in China: a study protocol of a prospective observational cohort study. BMJ Open 8(9): e023899.

3. Heysell SK, Moore JL, Peloquin CA, Ashkin D, Houpt ER (2015) Outcomes and use of therapeutic drug monitoring in multidrug-resistant tuberculosis patients treated in virginia, 2009-2014. Tuberc Respir Dis (Seoul) 78(2): 78-84.

4. Hubner W, Mc Nerney GP, Chen P, Dale BM, Gordon RE, et al. (2009) Quantitative 3D video microscopy of HIV transfer across T cell virological synapses. Science 323 (5922): 1743-1747.

5. Pasipanodya JG, Mc Illeron H, Burger A, Wash PA, Smith P, et al. (2013) Serum drug concentrations predictive of pulmonary tuberculosis outcomes. J Infect Dis 208(9): 1464-1473.

6. Tostmann A, Mtabho CM, Semvua HH, Van den Boogaard J, Kibiki GS, et al. (2013) Pharmacokinetics of first-line tuberculosis drugs in Tanzanian patients. Antimicrob Agents Chemother 57(7): 3208-3213.

7. Justine M, Yeconia A, Nicodemu I, Augustino D, Gratz J, et al. (2018) Pharmacokinetics of First-Line Drugs Among Children with Tuberculosis in Rural Tanzania. J Pediatric Infect Dis Soc 9(1):14-20.

8. Niward K, Davies Forsman L, Bruchfeld J, Chryssanthou E, Carlstrom O, et al. (2018) Distribution of plasma concentrations of first-line anti-TB drugs and individual MICs: a prospective cohort study in a low endemic setting. J Antimicrob Chemother 73(10): 2838-2845.

9. Zuur MA, Bolhuis MS, Anthony R, Den Hertog A, Van der Laan T, et al. (2016) Current status and opportunities for therapeutic drug monitoring in the treatment of tuberculosis. Expert Opin Drug Metab Toxicol 12(5): 509-521.

10. CDC (2006) Emergence of Mycobacterium tuberculosis with extensive resistance to second line drugs worldwide, 2000-2004. MMWR Morb Mortal Wkly 55(11): 301-305.

11. (2006) Extensively drug-resistant tuberculosis (XDR-TB) recommendations for prevention and control. Wkly Epidemiol Rec 81(45): 430-432.

12. Kempker RR, Barth AB, Vashakidze S, Nikolaishvili K, Sabulua I, et al. (2015) Cavitary penetration of levofloxacin among patients with multidrug-resistant tuberculosis. Antimicrob Agents Chemother 59(6): 3149-3155.

13. Strydom N, Gupta SV, Fox WS, Via LE, Bang H, et al. (2019) Tuberculosis drugs' distribution and emergence of resistance in patient's lung lesions: A mechanistic model and tool for regimen and dose optimization. PLoS Med 16(4): e1002773.

14. Heinrichs MT, Vashakidze S, Nikolaishvili K, Sabulua I, Tukvadze N, et al. (2018) Moxifloxacin target site concentrations in patients with pulmonary TB utilizing microdialysis: a clinical pharmacokinetic study. J Antimicrob Chemother 73(2): 477-483.

15. Sun T, Liu L, Wu A, Zhang Y, Jia X, et al. (2017) iTRAQ based investigation of plasma proteins in HIV infected and HIV/HBV coinfected patients - C9 and KLK are related to HIV/HBV coinfection. Int J Infect Dis 63: 64-71.

16. Auclair B, Mikota SK, Peloquin CA, Aguilar R, Maslow JN (2002) Population pharmacokinetics of antituberculous drugs and treatment of Mycobacterium bovis infection in bongo antelope (Tragelaphus eurycerus isaaci). J Zoo Wildl Med 33(3): 193-203.

17. Bijleveld Y, De Haan T, Toersche J, Jorjani S, Van der Lee J, et al. (2014) A simple quantitative method analysing amikacin, gentamicin, and vancomycin levels in human newborn plasma using ion-pair liquid chromatography/tandem mass spectrometry and its applicability to a clinical study. J Chromatogr B Analyt Technol Biomed Life Sci 951-952: 110-118.

18. Gao S, Wang Z, Xie X, You C, Yang Y, et al. (2018) Rapid and sensitive method for simultaneous determination of first-line anti-tuberculosis drugs in human plasma by HPLC-MS/MS: Application to therapeutic drug monitoring. Tuberculosis (Edinb) 109: 28-34.

19. Van den Elsen SHJ, Oostenbrink LM, Heysell SK, Hira D, Touw DJ, et al. (2018) Systematic Review of Salivary Versus Blood Concentrations of Antituberculosis Drugs and Their Potential for Salivary Therapeutic Drug Monitoring. Ther Drug Monit 40(1): 17-37.

20. Yew WW, Cheung SW, Chau CH, Chan CY, Leung CK, et al. (1999) Serum pharmacokinetics of antimycobacterial drugs in patients with multidrug-resistant tuberculosis during therapy. Int J Clin Pharmacol Res 19(3): 65-71.

21. Arsand JB, Jank L, Martins MT, Hoff RB, Barreto F, et al. (2016) Determination of aminoglycoside residues in milk and muscle based on a simple and fast extraction procedure followed by liquid chromatography coupled to tandem mass spectrometry and time of flight mass spectrometry. Talanta 154: 38-45.

22. Dijkstra JA, Sturkenboom MG, Hateren K, Koster RA, Greijdanus B, et al. (2014) Quantification of amikacin and kanamycin in serum using a simple and validated LC-MS/MS method. Bioanalysis 6(16): 2125-2133.

23. Le TH, Ng C, Chen H, Yi XZ, Koh TH, et al. (2016) Occurrences and Characterization of Antibiotic-Resistant Bacteria and Genetic Determinants of Hospital Wastewater in a Tropical Country. Antimicrob Agents Chemother 60(12): 7449-7456.

24. Kim HJ, Seo KA, Kim HM, Jeong ES, Ghim JL, et al. (2015) Simple and accurate quantitative analysis of 20 anti-tuberculosis drugs in human plasma using liquid chromatography-electrospray ionization-tandem mass spectrometry. J Pharm Biomed Anal 102: 9-16.

25.Zhang Y, Shen Y, Yin L, Qi T, Jia X, et al. (2019) Plasma Membrane Proteomic Profile Discovers Macrophage-capping Protein Related to Latent HIV-1. Curr HIV Res 17(1): 42-52.

26. Sivaraman T, Kumar TK, Jayaraman G, Yu C (1997) The mechanism of 2,2,2-trichloroacetic acid-induced protein precipitation. J Protein Chem 16(4): 291-297.

27. Heller DN, Clark SB, Righter HF (2000) Confirmation of gentamicin and neomycin in milk by weak cation-exchange extraction and electrospray ionization/ion trap tandem mass spectrometry. J Mass Spectrom 35(1): 39-49.

28. Keevil BG, Lockhart SJ, Cooper DP (2003) Determination of tobramycin in serum using liquid chromatography-tandem mass spectrometry and comparison with a fluorescence polarisation assay. J Chromatogr B Analyt Technol Biomed Life Sci 794(2): 329-335.

29. Mimoz O, Jacolot A, Padoin C, Quillard J, Tod M, et al. (1996) Influence of experimental rat model of multiple organ dysfunction on cefepime and amikacin pharmacokinetics. Antimicrob Agents Chemother 40(3): 819821.

30. Song SH, Jun SH, Park KU, Yoon Y, Lee JH, et al. (2007) Simultaneous determination of first-line anti-tuberculosis drugs and their major metabolic ratios by liquid chromatography/tandem mass spectrometry. Rapid Commun Mass Spectrom 21(7): 1331-1338. 


\section{ISSN: 2574-1241}

DOI: 10.26717/BJSTR.2021.34.005489

Lijun Zhang. Biomed J Sci \& Tech Res

(C) This work is licensed under Creative

Submission Link: https://biomedres.us/submit-manuscript.php

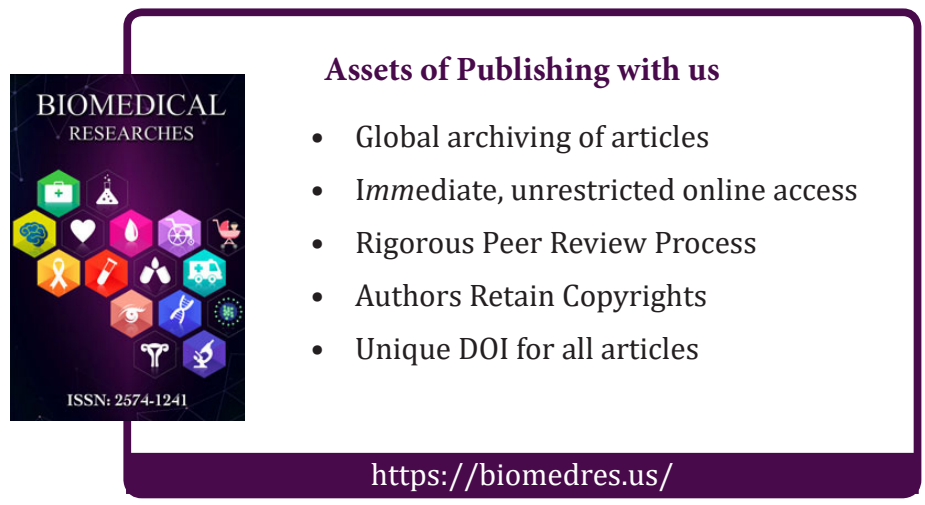

